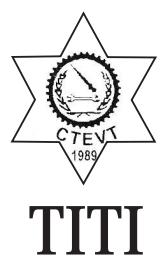

\title{
Understanding The Challenges Of Women In Non-traditional Occupations
}

\author{
Govinda Kumar Shrestha \\ Instruction Programme \\ Training Institute for Technical Instruction (TITI) \\ Sanothimi, Bhaktapur, Nepal \\ Email for correspondence: gks@ titi.org.np or gshrestha08@gmail.com
}

\begin{abstract}
This qualitative case study research was conducted to understand the perception of women in nontraditional occupations in Nepalese context. Seven participants from four nontraditional occupations, namely electrical, motorcycle mechanics (automobile), light vehicle driving and mechanical lathe operator were selected from Kathmandu valley. The data were collected using interview and focus group discussion.
\end{abstract}

The findings revealed that involvement of Nepalese women in non-traditional occupations are very nominal. It is due to the conventional thinking towards women that they should do only the household chores. Non-traditional occupations for Nepalese women have not been women-friendly, however, they may if they do not feel inferior to male and avoid hesitation to work in these professions. The biggest challenge for women in these professions is the societal disbelief on the women's work. They are behaved with suspicion by people and the society. Leg pulling and backbiting nature of people towards women in this profession are also the serious problems for them. Nevertheless, the female participants have got support from their family and organizations. Moreover, they have played significant roles from beginning to date to inspire them to continue their work.

Key words: Women, vocational training, nontraditional occupation and challenges

\section{Introduction}

Women have increasingly become more involved in the workforce following world war second. Paid employment of women has shifted from primarily traditional female- oriented jobs to more nontraditional, and previously male-oriented careers (Jones \& Domenico, 2006). Ever since the rise of the women's movement in the 1960s, the traditional activity of men and women has been significantly restructured and men's economic activity has also been affected by the wave of social change (Jones \& Domenico, 2006). Definitely, from the gender perspective, Nepalese women are also gradually seeking for their right of getting employment to 
uplift the economic status in their traditional occupation and non-traditional occupation as well.This study definitely focuses on the women's interest in highly paid job on non-traditional occupation for changing their lifestyle, society and culture. The state policy with respect to women empowerment on non-traditional trade is additionally relevant for gender equality against the male dominated society or working in favor of female empowerment (Ibrahim, 2014). So, this study will help the society to encourage women participation in male dominated occupation as well as reduce the gender misbalance.

In the Technical Education and Vocational Training (TEVT) sector of Nepal, several programs from government and non-government level have been launched for youth to uplift their economic status and reduce poverty. One of such programmers is vocational training through which they can sustain either with employment or self-employment (Khanal, 2013). In the beginning, these vocational trainings such as electrical, motor cycle mechanics, carpentry, village animal health worker, mason, welding, automobile, mechanical lathe operator, JCB operator, etc. were focused only for men. So we called these trainings as the non-traditional trade for women (Paudel, 2014). Women's participation in the skills is not traditional. So far, women's enrollment in TEVT sector is also very low. There are multiple causes of low participation of women in TEVT such as lack of access to technical schools, lower level of education in women, their involvement only in daily household work, domination of males in the society, lack of access of information and high level of poverty, etc. Research shows that only $27 \%$ women are involved in TEVT sectors overall in Nepal (Lamichhane, 2006, as cited in Paudel, 2014). From this data, it can be assumed that involvement of Nepalese women in non-traditional occupations is very nominal. This is due to the conventional thinking towards women "that women are confined only in the domestic works".

Almost all non-traditional occupations followed by
Nepalese women lie under Technical Education and Vocational Training (TEVT) sectors. So, the researcher searched and screened all the TEVT policies formulated by Council for Technical and Education and Vocational Training (CTEVT) because CTEVT is an autonomous and apex body of the TEVT sectors of Nepal. Regarding women's issues, the TEVT Skill Development Policy of Nepal 2064 has focused to expand the training programs to ensure the access and inclusion of women.

Nepal is a male-dominated and patriarchal society where women are considered subordinates to men virtually in every aspect of life. The economic contribution of women is significant, but largely unnoticed because their traditional role like taking care of most household chores is taken for granted. When employed, their wages are normally less than those paid to men. There have been efforts to increase the skill/wages employment to provide women with the opportunity for self-sufficiency; for example, women are trained from technical training providers in different skill training especially in the TEVT sectors which are male dominated and certified by "National Skill Testing Board' (NSTB) of Nepal by taking their skill tests. Women pre-dominantly are employed as clerical workers, child care providers, sales clerks, and other low skill/low wages employment, which do not lead to self-sufficiency. There are, definitely, some challenges for women to perceive non- traditional occupations positively. Challenges include sex role socialization, discrimination and harassment, transportation and child care issues, and the hazardous workplace and potential job related injuries (Zula, 2014).

While skilled trades can offer many positive benefits for women, a strong deterrent is the underlying feeling that "it's still a man's world." Women are discouraged or excluded from the skilled trades because the experiences of women in non-traditional occupations are diverse and complex. In some cases, occupations have already been labelled as male or female-oriented, and strong forces act to keep those gender assignments. These labels can act as a 
mechanism for members/groups to steer women to avoid jobs that are typed as male without providing the right sort of information or communication about careers (Scullen, 2008).

In Nepalese context, the participation of women in the technical skills and enterprising skills is not the tradition. It requires innovative ways and means to enable and stimulate women's participation in such types of skills and link them to jobs, help them retain and grow in their jobs as well as support their enterprise and ensure their sustainability (Paudel, 2014). There are many myths around working in non-traditional trade areas which are treated as fact and provide reasons for people to continue maintaining the status quo which prevents women entering these trades. (Shewring, 2008).It is therefore, prompt questions are raised, "why do such beliefs exist in society?" and "why do people not want to see the involvement of women in such occupations?'There are some reasons behind these problems. Among them, Nepalese society, culture, caste system, religion and social exclusion are the possible major factors. Traditionally, Nepalese society has divided the duties and tasks of men and women which they ought to do or ought not to do. Due to this reason, women hesitate to involve in the "men's" work. It is mostly influenced by the orthodox views. Likewise, the most unique problem with Nepal is the caste system and its system of work division. This is also a reason that people are reluctant to involve in works other than that of their own castes. However, thinking of people is changing about it gradually and they are showing interest to do each and every job regardless of what jobs have been assigned traditionally. Still today some people do not allow female members of their family to work outside their houses. They do not want to see the involvement of women in outside world of work especially in the non-traditional occupations. Indeed, this is due to the problem of our family and social system that perceives women as a weaker sex to do all work and consequently make them really weaker.

There are numerous researches conducted globally.
However, in Nepalese context, there seems a dearth of relevant study. When the researcher reviewed the existing literature about nontraditional occupations for women in the international context, it was found that most of the researchers have focused on how the non-traditional occupations have been difficult for women from the point of view of gender and sexuality in transport and construction work. Similarly, some research have also focused on that women love the non-tradition job but why they do not want to do continue for long time and what are the reasons behind this. Likewise, some researches are also related to what factors play an important role to make the women hesitated to be involved in male dominated occupations. However, the challenges for women involved in non-traditional occupations have not been explored in Nepalese context. So, there is some certain gap between existing researches and this research. This study has focused on challenges for Nepalese women involved in the male dominated occupation and the perceptions of women on such occupations.

\section{Research Questions}

1. What are the challenges of women who are involved in non-traditional occupations?

\section{Case Study as My Research Method}

Case study research method is "an empirical inquiry that investigates a contemporary phenomenon within its real-life context; when the boundaries between phenomenon and context are not clearly evident; and in which multiple sources of evidence are used" (Yin, 2003). This method enables a researcher to closely examine the data within a specific context. In most cases, a case study method selects a small geographical area or a very limited number of individuals as the subject of study. Case studies, in their true essence, explore and investigate contemporary real-life phenomenon through detailed contextual analysis of a limited number of events or conditions, and their relationships (Zainal, 2007). Case studies are considered useful in research as they enable researchers to examine data at the micro level. Case studies can be a practical solution when 
a big sample population is difficult to obtain (Zainal, 2007). So the researcher investigated the contemporary real life phenomenon of women in nontraditional occupations through detailed contextual analysis of a limited number of participants, and their relationships.

The qualitative case study facilitates to explore the phenomena within the context using variety of resources. It helps to see the issues through variety of lenses which allow for multiple facets of the phenomena to be revealed and understood (Baxter $\&$ Jack, 2008). So, the researcher explored the phenomena within the context using the variety of resources. Study on the understanding of the challenges of non-traditional occupations for women in Nepal fits here as it focuses to answer the process question (Yin, 2003). So the researcher has chosen the social constructivist worldview and will comprise observation, focused group discussion, open-ended questions. Social constructivism develops the subjective meaning of participants' experiences towards certain objects or things which are varied and multiple (Creswell, 2008). In this research, there were five cases of each participants. They were electrical, motorcycle mechanics, light vehicle driving and mechanical lathe operator. Two participants were from same occupation that is motorcycle mechanics (automobile).

\section{Challenges and Opportunities of Women in Non- traditional Trades}

In some trades like non-traditional occupations and others maintaining a balance between work and family can be a difficult task if they are a single parent. This is especially true in such occupations like industrial construction where job sites are so remote that employees have to temporarily live in or near the site (Government of Alberta 2013, 2009). Women simply by competently performing their work in these male dominated environments, were enabling fissures in the stereotypes that circulate about women's bodily strength, feminine movement and shape (Annette, B., 2006, p. 13).
Regarding the challenges and opportunities for women in nontraditional occupations, stakeholders observed the challenges for them like: unfavorable working time, difficulty in going outside for official work, difficulty in taking extra-work besides office hour, difficulty in taking heavy work due to the abdominal problem etc. Wright (2011) found her research that some difficulty to greater participation of women in such jobs due to the structural barriers like long working hours, shift patterns and system of workplace training that affect women's participation. Despite these problems, Mr. Chitra Sharma said that there are so many opportunities for women in this profession. Women can get career opportunities in their professional life. They can be self-employed to maintain a standard life. Likewise, there are also opportunities to travel abroad as exposure visits from the organization for the employees. As per the stakeholder's evaluation, some participants have got excellent performance and some are very good performers. On the whole all are good. The major evaluation criteria are teaching pedagogy, punctuality, student's feedback, pass percentage of students in skill test, obedience, etc.

As researcher, I think women can perform this job despite the facing the problems. They know that no one's work in the world of work. I think, women should face every kind of challenges and must be competent in their work which enhances the credibility to others. In this situation, they can receive enough support from others through which they can get greater responsibility. Moreover, fair evaluation in their work place is also the critical factor to give them encouragement in such profession for further continuation. So, if the organization evaluates fairly, women can perform their job in well manner way.

\section{Social Challenges and Opportunities of Women}

In their professional career all the women participants have found various social obstacles and opportunities in this profession. According to them, the biggest problem they have faced is lack of belief on women's work. Society underestimates women's work 
perceiving that they cannot do work easily and thinks negatively. So, they believe that it takes time to make women's work in this profession socially acceptable. During the focus group discussion also, participants said that there is leg pulling culture in the society. They say nothing in front of them and backbite that these women who have come in this professions are illiterate and characterless. In the FGD, one more participant took part in discussion. She was a JCB operator. She share that when she went to the outside the valley as JCB operator after completion of her JCE training, a large number of people came to see her as they were surprised that a woman was operating JCB. Mina Ahdhikari shares that when she goes to the highway by taking her vehicle, she has to tackle problems from male drivers, such as blowing horn unnecessarily, not letting them go easily, etc. Another challenge for them was the difficulty in changing the dress while working in construction site or worksite. Likewise, they have sometimes suffered from irritation and harassment from people with questions like why they chose this profession while it is the male's work. Regarding the opportunities, they have a single voice that government, semi-government and private organizations give high priority to women candidates as compared to male in the case of non-traditional occupations. Among the five participants, Rita Thapa has started her own business (workshop).

Challenges include sex-role socialization, discrimination and harassment, transportation and childcare issues. The nontraditional workplace may be hazardous which requires special safety clothing and equipment to extreme weather conditions and job related injuries. Beyond work site issues, there are social challenges to be considered: being the sole female employed and non- supportive family and friends and so on. These challenges need not be a hindrance for females interested in non-traditional employment; there are numerous support services, support groups, and social agencies which are willing to help women overcome any of these barriers (WOW, 2013, as cited in Zula, 2014). Many occupations do not require a 4-year college degree, including many service sector jobs and skilled trades. Non-college women tend to hold lower-paying jobs with fewer opportunities for advancement compared to college men. Many employment and training programs for women focus on increasing their numbers in jobs where men dominate, which tend to be higher paying and provide more opportunities for advancement (Mastracci, 2003, as cited in Zula, 2014).

As researcher, I think creation of unbelievable situation for women in non-traditional occupations is due to the structure of the society. Despite facing several social problems, women have got several opportunities by getting job. Self-employment makes them more courageous, self-respectful, sustainable, etc.

\section{Family Related Challenges and Opportunities} As the professional carrier is concerned, the participants have not faced any kind of challenges and problems from their family members. Instead, they have encouraged them continue and helped by creating a favorable working environment. Definitely, as women, they need family support to continue their profession. According to Samita Ghimire, without family support, she could not imagine herself at all to be in this profession. Besides, they have increased income sources by involving in this profession.

The parental expectations may influence the occupations and roles children select for themselves (Rosenwasser, 1982, as cited in McNulty, 2013). Greenfield, Holloway and Remus (1982) found that men are motivated towards professions that deal with inanimate objects, e.g. engineering while women are motivated towards professions that involve interaction with people like teaching and nursing. Family system theory posits that while in an ideal situation relationships between family members exist in a state of balance or equilibrium (each reciprocally affecting the psychological state of the other, including possible physiological effects), maintaining such equilibrium during expatriation is often a 
challenge. This can be due to internal and external factors that exert pressure on a family's equilibrium as they attempt to adjust to their new environment (Brown, 2008, as cited in McNulty, 2013).

Women can enter into this profession if they can get support from family members so that they do not face any kinds of family problems in their professional career after getting involved in such profession. With full support, they can increase income sources from these professions.

\section{Personal/Professional Challenges and Opportunities}

Definitely the participants have personal/professional challenges and opportunities in their professional career. As challenges, they have to compete with men and need to show their competency and confidence to make others believe in women's work. Likewise, another personal challenge for women is to work physically in construction sites. In some professions they even have to break concrete wall and bricks. At such conditions, they have felt some discomfort in this profession. Most of the time, they have to work and compete with men continuously as per the nature of work. However, if they work competently and persuade people of their abilities, they can get support from male and increase the possibility of getting additional responsibility from employer which gives them further opportunities. As a researcher, I found that they were all competent and confident in theirprofession. For this, it is a must for women to gain belief in their work for others in this profession.

\section{Findings}

Based on the interviews and focus group discussion with the participants, and subsequent interpretation of their data, following findings have been explored: Regarding the understanding of women in nontraditional occupations, it is found that all the participants have been involved in non-traditional occupations with the inspiration from their family members. They were getting continued motivation and support from them till the date ever since their involvement in the profession. All the participants believed that non-traditional occupations for Nepalese women might not be women friendly for the time being in Nepal, but they also agreed that it is definitely possible in the future if the women do not feel weaker than men and avoid hesitation to work in this profession. All the participants said that the society did not believe women's work initially and even if they believed, they would not take it positively. Due to the low involvement of women in this profession in Nepal, most of the time they were obliged to be involved with males while working in their work places. At such circumstances, they are even eyed with suspect for having unethical relationships with their male co-workers. On the contrary, the findings showed that there were people who encouraged them as positive thinkers to continue with their respective professions. With respect to organization and family members, they were found to have felt proud of them. They had got full support from them. It was because, they had played significant role to continue their work efficiently and effectively.

Regarding women in non-traditional occupations, the researcher explored that stakeholders (employer and parents) were satisfied with the performance of participants. Due to the minimal number of women involved in non-traditional occupations, they had believed that women who were involved in such professions became role model for other women. Stakeholders also disclosed that participants performed their job well and were equally competent as men. Stakeholders had seen changes in participants' living standards, behavior, communication skills, confidence level, and trend towards fashion. However, they had also observed challenges for women in this profession, such as unfavorable working time, difficulty in going outside for official work, difficulty in taking extra-work besides office hour, difficulty in taking heavy work due to the abdominal and other feminine problem etc. They also perceived that women can get opportunities for employment in government, semigovernment and private organization as well as in being self-employed. An employer revealed that 
upon carrying out fair evaluation, some were excellent performers while the rest were good performers. The evaluation criteria for them were punctuality, obedience, teaching pedagogy etc.

While exploring challenges and opportunities for women in non-traditional trades, all the participants shared that they had to face some serious social problems. According to them, the biggest problem was that the society does not believe in women's work. In the opinion of participants, leg pulling and backbiting nature of people towards women in this profession are also the serious problems for them. It is found that light vehicle female drivers faced harassment, such as male drivers blowing horns on them intentionally; not letting their vehicles go and so on. This is due to the male domination in driving profession. Changing dress in workplace is found to be another problem for women. They explained that most of the works in such professions are skill based and they have to work either in the workshop or construction sites. In such situation, they are unable to get changing rooms or appropriate places to change the dress according to the needs. Beside these challenges, they also faced harassment from the people who often ask them the reason for choosing such profession and discourage saying that they cannot perform the job like male can. The social challenges seem bigger for them as compared to family challenges and challenges from employers. However, one of the common challenges they had to face in their workplaces was lack of support from their colleagues. Sustaining themselves and competing with male entrepreneurs posed another big challenge for women running their own enterprises. An explicit finding in the paper is the challenge for women related to physical strength. The participants working in construction field have to face a lot of difficulties such as breaking concrete wall and bricks and thus make the customer be skeptic about their competencies.

All the participants were involved in non-traditional occupations through the family inspirations, selfawareness and self-confidence. In Nepalese context, the drift of women shifting to non-traditional occupations is in the initial phase. In fact, involvement of women in non-traditional occupations is very nominal. Furthermore, most of the women are still unknown about such professions. They are facing challenges from the society which does not want them to see in such non-traditional works and does not believe in their competencies. Similarly they face problems from the male counterparts in the same profession who do not step back in harassing; from colleagues who would not always help them with complex tasks; and from customers in the construction field who are less convinced of their physical strengths. Despite the challenges participants got support from family and employers and were also satisfied with their respective jobs. These participants were found to have been performing well in their work places.

\section{Conclusion}

Women have involved in non-traditional occupation generally from the great inspiration of their family members. In fact, family members have become the crucial factors for the participants in continuing this profession. Joining non-traditional occupations in Nepal is the new practice for women. Society still does not believe women's work and doesn't look positively to women. Majority of women are still unknown such professions. The nature of the occupation has made it male dominated and unfriendly for women. This has led women believe that since this is a wrong profession, they cannot compete with men. Due to this reason, limited number of women has involved in this occupation. Women who are engaged in such profession face unexpected problems such as unfavorable working time, difficulty in taking extra work beside office hour, difficulty in taking heavy work which is not preferred by employers, etc. Some social problems include lack of trust in their competency and ability, leg pulling, backbiting and discouragement, etc. Women also face harassment from their male counterparts causing insecurity to their dignity. Awkwardness to use common changing room, difficulty to work while having feminine problems; and performing heavy 
tasks are also common problems for them.

However, the face of this perception is changing. Their family and employers are positive towards the emergence of women in non-traditional occupations. Employers have encouraged the participation of women due their sincerity, obedience and punctuality. Employers are being convinced that they are capable of performing their job well and are equally competent as men, be it in a workshop or a construction site. To compete well, women face more challenges than men. In spite of the challenges, they have taken this profession as women-friendly as they have empowered themselves instead of feeling weaker than male and avoided their existing hesitation. Similarly, women involved in nontraditional occupation, have shown competencies and confidence in the work that they are equally capable as men to sustain and grow professionally. As professional career is concerned, they have not faced remarkable problems so far.

\section{References}

Annette, B. (2006). Doing a man-sized job: A study of women in non-traditional trades. Australian TAFE Teacher, 40(2).

Baxter, P., \& Jack, S. (2008). Qualitative case study methodology: Study design and implementation for novice researchers. Ontario, Canada: McMaster University.

Creswell, J. W. (2008). Qualitative inquiry and research design. New Delhi: Sage.

Domenico, D., \&Jones, K. H. (2006). Career aspirations of women in the 20th century.Journal of Career and Technical Education, 22(2).

Government of Alberta, Human Services. (2013). Women in nontraditional occupations stories to inspire. Retrieved from https://alis.alberta.ca /pdf/cshop/winto.pdf

Ibrahim, Z. (2014). Empowerment at STAR and the role of culture. Retrieved from ht tps://www.ucviden.dk/student portal/files/25407957/Empowerment _at_STAR_and_the_role_of_culture.pdf

Khanal, G. (2013). TVET policy 2012. Technical and Vocational Education and Training (TVET) Development Journal.

McNulty, Y. (2013). Women as female breadwinners in non-traditional expatriate families: Status reversal marriages, single parents, split families, and lesbian partnerships. In K. Hutchings \& S. Michailova (Eds.), Research handbook on women in international management. UK, Edward Elgar.

Paudel, B. R. (2014). Skills and enterprise for the transformation of women's lives in Nepal. Retrieved from http: kusoed.edu.np/ertsymposium 2014/ertpapers/ Bala Ram Paudel.pdf

Scullen, J. (2008). Women in male dominated trades. It's still a man's world. Canada, Saskatchewan Apprenticeship and Trades Certification Commission.

Shewring, F. (2008). Supporting women in non traditional trades. New South Wales, Australia: Illawara Institute.

Yin, R. K. (2003). Case study research design (3rded.). New Delhi, Sage.

Zainal, Z. (2007). Case study as research method. Malaysia: University Technology.

Zula, K. (2014). The future of nontraditional occupations for women: A comprehensive review of the literature and implications for workplace learning and performance. Journal of Diversity Management, 9. 